\title{
Differences in locomotor behavior revealed in mice deficient for the calcium-binding proteins parvalbumin, calbindin D-28k or both
}

\author{
Maria A. Farré-Castany a,b, Beat Schwaller ${ }^{\mathrm{a}, *}$, Patrick Gregory ${ }^{\mathrm{a}}$, Jaroslaw Barski ${ }^{\mathrm{c}}$, \\ Céline Mariethoz $^{\mathrm{b}}$, Jan L. Eriksson ${ }^{\mathrm{b}}$, Igor V. Tetko ${ }^{\mathrm{b}, \mathrm{g}}$, David Wolfer ${ }^{\mathrm{d}}$, Marco R. Celio ${ }^{\mathrm{a}}$, \\ Isabelle Schmutz ${ }^{\mathrm{e}}$, Urs Albrecht ${ }^{\mathrm{e}}$, Alessandro E.P. Villa ${ }^{\mathrm{b}, \mathrm{f}}$ \\ ${ }^{a}$ Unit of Anatomy, Department of Medicine, University of Fribourg, CH-1700 Fribourg, Switzerland \\ ${ }^{\mathrm{b}}$ Neuro-heuristic Laboratory, University of Lausanne, CH-1005 Lausanne, Switzerland \\ ${ }^{\mathrm{c}}$ Max-Planck-Institute of Neurobiology, AG Cellular Dynamics, Am Klopferspitz 18, 82152 Martinsried, Germany \\ ${ }^{\mathrm{d}}$ Institute of Anatomy, University of Zurich, Switzerland \\ ${ }^{\mathrm{e}}$ Unit of Biochemistry, Department of Medicine, University of Fribourg, CH-1700 Fribourg, Switzerland \\ ${ }^{\mathrm{f}}$ Laboratoire de Neurobiophysique, INSERM U 318, Université "Joseph Fourier" Grenoble 1, France \\ ${ }^{\mathrm{g}}$ Institute for Bioinformatics, GSF, Ingolstädter Landstrasse 1, D-85764 Neuherberg, Germany
}

\section{Abstract}

We investigated the role of the two calcium-binding proteins parvalbumin (PV) and calbindin D-28k $(\mathrm{CB})$ in the locomotor activity and motor coordination using null-mutant mice for PV (PV-/-), $\mathrm{CB}(\mathrm{CB}-/-)$ or both proteins ( $\mathrm{PV}-/-\mathrm{CB}-/-)$. These proteins are expressed in distinct, mainly non-overlapping populations of neurons of the central and peripheral nervous system and PV additionally in fast-twitch muscles. In a test measuring repeated locomotor activity during 18-20 days, the analysis revealed a slightly increased activity in mice lacking either protein, while the lack of both decreased the number of beams crossed during active periods. An increase in the characteristic speed during the first 8 days could be attributed to PVdeficiency, while the elimination of $\mathrm{CB}$ in $\mathrm{CB}-/-$ and double-KO mice decreased the percentage of fast movements at all time points. In the latter, additionally a reduction of the fastest speed was observed. The alterations in locomotor activity (fast movements, fastest speed) strongly correlate with the impairment in locomotor coordination in mice deficient for CB evidenced in the runway assay and the rotarod assay. The graded locomotor phenotype $(\mathrm{CB}>\mathrm{PV})$ is qualitatively correlated with alterations in Purkinje cell firing reported previously in these mice. The presence or absence of either protein did not affect the spontaneous locomotor activity when animals were placed in a novel environment and tested only once for 30 min. In summary, the lack of these calcium-binding proteins yields characteristic, yet distinct phenotypes with respect to locomotor activity and coordination.

Keywords: Parvalbumin; Calbindin-D28k; Knockout mice; Locomotor activity; Purkinje cells

\section{Introduction}

Parvalbumin (PV) and calbindin D-28k (CB) are high-affinity calcium-binding proteins (CaBPs) of the EF-hand family which are expressed in distinct classes of neurons [1], for a general review, see $[2,3]$. They are implicated to contribute to the regulation of $\mathrm{Ca}^{2+}$ homeostasis by acting as cytosolic $\mathrm{Ca}^{2+}$ buffers [4-6] and recent experiments on CB suggest that this protein

\footnotetext{
* Corresponding author at: Unit of Anatomy, Department of Medicine, University of Fribourg, CH-1700 Fribourg, Switzerland. Tel.: +41 2630085 08; fax: +41263009732.

E-mail address: Beat.Schwaller@unifr.ch (B. Schwaller).
}

might have additional functions as a $\mathrm{Ca}^{2+}$ sensor [7,8]. PV is almost exclusively expressed in inhibitory GABAergic interneurons in different regions including the neocortex, cerebellum, hippocampus and the reticular nucleus of the thalamus (RTN) of the mammalian brain and also in few projection neurons. CBpositive cells include both, interneurons and projection neurons including pyramidal cells. Co-expression of $\mathrm{PV}$ and $\mathrm{CB}$ is rare and the only clearly defined neuron population expressing high levels of both CaBPs is the Purkinje cells of the cerebellum [4,9]. Additionally, $\mathrm{PV}$ is expressed in fast-contracting muscles [10].

In recent years, the generation of knockout mice for PV [11], CB [12], as well as the CB antisense transgenic CB-deficient 
mice [13] have contributed to the understanding of the physiological role of these CaBPs. Previous work reported several physiological alterations at neuronal and muscular levels in these animals. PV $-/-$ mice revealed electrophysiological alterations associated with PV-expressing cortical neurons [14], cerebellar stellate and basket cells $[15,16]$ and hippocampal PV-immunoreactive interneurons [17]. CB-/- mice showed impairment in motor coordination associated with altered synaptic $\mathrm{Ca}^{2+}$ transients in Purkinje cell dendrites [12]. Furthermore, expression of $\mathrm{PV}$ and/or $\mathrm{CB}$ was reported to be altered in human patients and animal models of epilepsy and other neurological disorders. A loss of CB immunoreactivity in a majority of dentate granule cells was seen in mesial temporal lobe epilepsy (mTLE) patients [18]. Loss or decreased immunoreactivity to PV and CB from GABAergic neurons was observed in epileptic gerbils [19] and in experimental rats with induced cortical displasia [20]. Moreover, reduced immunoreactivity for $\mathrm{PV}$ and/or $\mathrm{CB}$ was reported in surviving cerebellar Purkinje cells [21] of patients with spinocerebellar ataxia-1 (SCA-1) and in an animal model using SCA-1 transgenic mice [22]. Decreases in PV expression were one of the most consistent findings in postmortem brains of patients with schizophrenia, bipolar disorder and major depression [23] and also downregulation of CB expression was reported before [24]. The results obtained in human patients and genetically modified mice clearly indicate that the presence or absence of PV or CB has significant effects on synaptic transmission and are likely to have profound effects at the systemic level including behavior, learning or memory. In this report, the influence of PV and CB on spontaneous locomotor activity and motor coordination was investigated using mice deficient for PV, $\mathrm{CB}$ or both. This former analysis is considered essential to reveal basic defects in sensory motor processing [25], which should be taken into account before performing more complex behavioral tests in view to detect putative links to neuropathologies. Mice were either tested in a novel environment for $30 \mathrm{~min}$, in the second paradigm, animals were tested 18-20 times in 15-min trial sessions and finally the motor coordination was assessed on the runway assay previously described for the $\mathrm{CB}-/-$ mice [12] and on the rotarod. All three groups of mice did not exhibit any obvious behavioral alterations when observed under standard housing conditions $[11,12,26]$. Preliminary results related to this study have been presented in abstract format [27].

\section{Materials and methods}

\subsection{Subjects}

The subjects for the analysis of repeated locomotor activity were 97 female mice, on average 5 months old and weighing $26-29 \mathrm{~g}$. The design of the study aimed to minimize the number of experimental animals and all experiments were performed with permission of the local animal care committee and according to the present Swiss law and the European Communities Council Directive of 24 November 1986 (86/609/EEC). Mice were housed in groups of three to four individuals on either a $12 \mathrm{~h} / 12 \mathrm{~h}$ light/dark cycle with light onset at 7 a.m. with free access to food and water. In this study we analyzed PV $-/-$ mice produced from targeted E14 cells [11] with either a mixed $\mathrm{C} 57 \mathrm{BL} / 6 \mathrm{~J} \times 129 \mathrm{OlaHsd}(\mathrm{B} 6 \times 129 \mathrm{P} 2)$ or a B6 background (backcrossed for eight generations; $\mathrm{B} 6 \mathrm{PV}-/-$ ). The mixed background $\mathrm{PV}-/-$ mice were maintained as a homozygous stock with at least 10 intercrosses generations. The breeding scheme among mixed PV-/- was aimed to avoid homozygous fixation of allele combinations not related to the PV gene locus by systematic randomizing of breeder pairs from the original $\mathrm{PV}-/-$ homozygotes derived from heterozygous $(\mathrm{PV}+/-)$ couples. As the control groups for the mixed and B6 background, an $\mathrm{F} 1$ generation of $\mathrm{B} 6$ and 129P2 or $\mathrm{B} 6 \mathrm{PV}+/+$ littermates from heterozygous $\mathrm{B} 6 \mathrm{PV}+/-$ breedings was used, respectively. Also for $\mathrm{CB}-/-$ mice produced from R1 stem cells [12], two different genetic backgrounds were tested: mice with a mixed background B6 and 129R1 (129Sv $\times 129 \mathrm{SvJ})^{\prime}$ [28], or mice that had been backcrossed to $\mathrm{B} 6$ for seven generations (B6CB $-/-$ and $\mathrm{B} 6 \mathrm{CB}+/+$, both derived from heterozygous $\mathrm{B} 6 \mathrm{CB}+/-$ matings). Control mice for the B $6 \times 129 \mathrm{R} 1 \mathrm{CB}-/-$ background were either $\mathrm{B} 6 \times 129 \mathrm{R} 1 \mathrm{CB}+/+$ littermates produced from heterozygous $\mathrm{B} 6 \times 129 \mathrm{R} 1 \mathrm{CB}+/-$ breedings or a $\mathrm{F} 1$ generation of B6 $\times 129 \mathrm{~S} 5$, which was assumed to be similar to $\mathrm{B} 6 \times 129 \mathrm{R} 1$ [28]. $\mathrm{PV}-/-\mathrm{CB}-/-$ mice, which were bred from the mixed $\mathrm{CB}-/-$ and $\mathrm{PV}-/-$ mice [26] have a genetic background of $\mathrm{B} 6 \times 129 \mathrm{P} 2 \times 129 \mathrm{R} 1$ and were compared to a pool of 20 mice consisting of 10 each with a $\mathrm{B} 6 \times 129 \mathrm{P} 2$ or B6 $\times 129$ S5 background. Wildtype (WT) animals used in this study included B6, 129S5, 129P2 and $\mathrm{F} 1$ generations of $\mathrm{B} 6 \times 129 \mathrm{~S} 5$ and $\mathrm{B} 6 \times 129 \mathrm{P} 2$. All animals, including WT ones, were genotyped by PCR as described before [26]

\subsection{Analysis of repeated locomotor activity}

The animals were analyzed in a black rectangular box $(380 \mathrm{~mm}$ wide $\times 420 \mathrm{~mm}$ long $\times 400 \mathrm{~mm}$ high) located in a soundproof room. The box was open at the top and illuminated by a dim light. Three parallel infrared beams (labeled F1, F2, F3) were used to detect the movements of the animals (Fig. 1). The distance between $\mathrm{F} 1$ and $\mathrm{F} 2$ was $140 \mathrm{~mm}$ and between $\mathrm{F} 2$ and $\mathrm{F} 3$ was $80 \mathrm{~mm}$. The investigator left the soundproof room before the beginning of the recording and monitored the mouse's behavior from the outside by means of a video camera placed on the ceiling over the box. Digital pulses were generated when the infrared beams were interrupted and the time stamp of these occurrences was recorded by a Macintosh IIfx (Apple Computers, Cupertino, CA) personal computer equipped with digital acquisition boards (National Instruments, Austin, TX). All signals were recorded at a time resolution of $1 \mathrm{~ms}$ and stored digitally for further off-line analysis.

All experiments were performed between 1 p.m. and 7p.m. Mice of either genotype or genetic background were subdivided into groups and tested in different series. Each series consisted of three to four different groups, e.g. different genotypes (wildtype, $\mathrm{PV}-/-, \mathrm{CB}-/-$, and $\mathrm{PV}-/-\mathrm{CB}-/-$ ) or different genetic backgrounds $(\mathrm{B} 6,129 \mathrm{P} 2, \mathrm{~F} 1 \mathrm{~B} 6 \times 129 \mathrm{P} 2)$ and of three to four animals of each group. Thus, a series consisted on the average of 12 mice from at least three different groups. For each series the passage order was randomized at the first session and varied from day to day following the initial randomization scheme. The mice were recognized by color codes and numbers. In all experiments, the breeder kept the correspondence of code and genotype secret to the investigators until the end of all experiments. During one session a mouse was placed in the apparatus close to the F1 infrared beam (Fig. 1) and allowed to move unhindered during $15 \mathrm{~min}$. The sessions occurred at a rate of one per day. Mice were analyzed

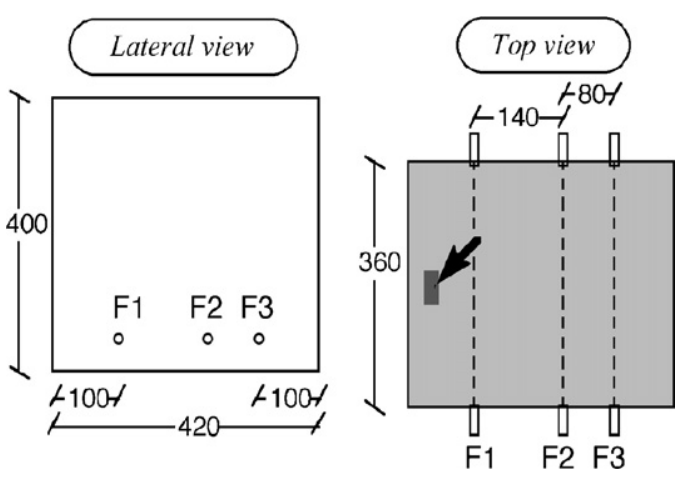

Fig. 1. Schematic diagram of the experimental box. Measures are indicated in millimeters. Three infrared beams F1, F2 and F3 are used to detect the movements of the mice. Note that mice were placed between the wall and the F1 beam (indicated by the arrow) at the beginning of each trial. 


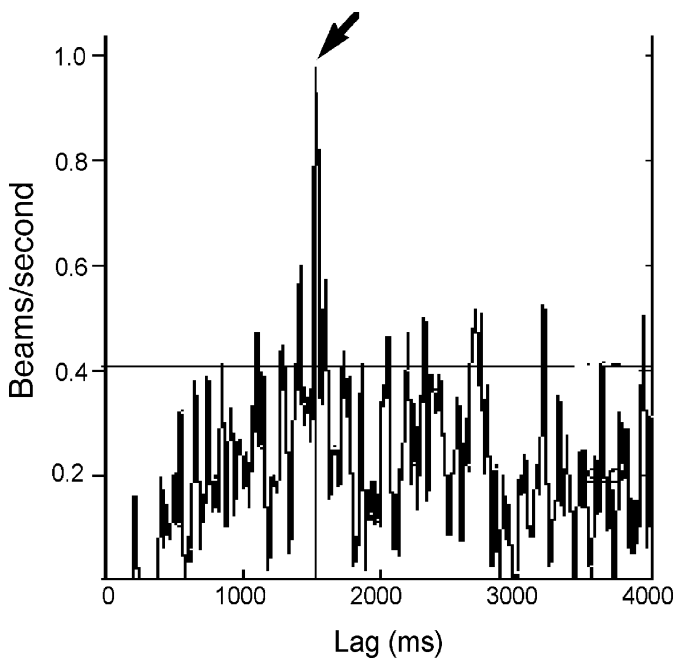

Fig. 2. Crosscorrelogram of F1 beam crossings as a function of the lag after F3 beam crossings. The arrow indicates the mode of the distribution used to calculate the characteristic speed. The $y$-axis is scaled in rate units (beams crossed/second) and smoothed after convolution with a moving Gaussian-shaped bin of $25 \mathrm{~ms}$ width. The dashed line corresponds to $99 \%$ confidence limits calculated assuming that a Poisson distribution underlay the time series. This figure illustrates the distribution of one particular mouse.

during 18-20 sessions, yielding an overall time of observation of at least $4.5 \mathrm{~h}$ per animal. Sessions for the entire experiments were divided into four blocks: block 1 (days 1-3), block 2 (days 4-8), block 3 (days 9-13) and block 4 (days 14-18 or 20). Block 1 of each mouse was analyzed separately and yielded information about the spontaneous locomotor activity in a novel environment. The data from all 18-20 sessions was pooled and analyzed as "repeated locomotor activity".

For each mouse we defined a set of parameters that were used to describe individuals as well as locomotor activity grouped by genotype. Grouped values are expressed as the mean \pm standard error of the mean (S.E.M.). Statistical evaluation of genotype factor was assessed by non-parametric Kruskal-Wallis and Mann-Whitney $U$-tests. The average activity (AA) was expressed in arbitrary units corresponding to the total number of beam crossings divided by the total duration of the tests. This corresponds to a number of events per unit of time. Whenever the mouse remained without crossing any beam during 10 consecutive seconds this was counted as one inactive period with regard to locomotion. We defined the parameter locomotor inactivity (LIA) as the ratio of the time spent in inactive periods divided by the total duration of the tests. Based on this, we defined a locomotor index $\mathrm{LI}=\mathrm{AA} /(1-\mathrm{LIA}) \times 100$. This index referred to the number of beam crossings per active time times 100 , thus providing a more objective parameter of the subject's mobility.

The time stamps of each beam crossing were used to construct time series. We computed the crosscorrelogram of the time series associated with the two most distant infrared beams crossings, thus corresponding to the distribution of F3-F1 crossings as a function of the time interval between F3 after F1 crossings. The characteristic speed (expressed in $\mathrm{mm} / \mathrm{s}$ ) was defined as the distance between $\mathrm{F} 3$ and $\mathrm{F} 1$ (equal to $220 \mathrm{~mm}$ ) divided by the time lag corresponding to the mode of this distribution measured on the crosscorrelogram of F1 beam crossings as a function of the lag after F3 beam crossing (Fig. 2). The ordinate of the crosscorrelograms is related to time in order to standardize for different total assay length. From the same crosscorrelogram also the fastest speed (expressed in $\mathrm{mm} / \mathrm{s}$ ) was calculated. In addition, we counted the number of times a subject was crossing two adjacent beams (F2-F3) within a delay of $40 \mathrm{~ms}$. These events were called fast movements and we analyzed the proportion of these events with respect to the total number of beam crossings. At the beginning of each session, the subjects were placed in the apparatus close to the F1 beam.

\subsection{Spontaneous activity exploring an unfamiliar environment}

Analysis of locomotor behavior in an unfamiliar environment was performed by means of the multi-parameter activity monitor Tru Scan and its associated software (Coulbourn Instruments, Allentown, USA). To record the activity, the mouse was placed in a cage-arena $(25.9 \mathrm{~cm} \times 25.9 \mathrm{~cm})$ equipped with two rings of infrared sources and sensors (beam spacing $1.52 \mathrm{~cm}$ ) mounted to register all horizontal and vertical (rearing) movements. For each mouse, the whole trial lasted $30 \mathrm{~min}$ subdivided into 1-min bins. The move number is defined as successive coordinate changes, with no rest, for at least 1 sample interval. Move times represent the cumulative duration of all $X-Y$ movement episodes, whereas the rest time is the difference between $X-Y$ movement time and the length of data interval. Total distance is the sum of distances between successive coordinates. Marginal distance is defined as a total distance traveled while within a twobeam margin of the walls of the cage, while center distance applies for the total distance while outside this region. Center and marginal time inform about the time periods spent by animals in the above-defined parts of the cage-arena.

Movements in the $Z$-axis are described as vertical breaks, which were defined as disruptions of infrared beams of the upper sensor ring, which can only occur if the mouse stands on its hind extremities having no ground contact with the forelimbs. Results for all parameters are mean values \pm S.D. calculated for 1min bins. Statistical analysis was performed by means of ANOVA-single factor test.

\subsection{Runway assay}

Tests were performed by the same experimenter on age- (4-6 months old), sex-, and weight-matched animals (group sizes were between 8 and 20 mice). Each mouse was tested in five consecutive trials per day for 5 days on a rod $(100 \mathrm{~cm} \times 2 \mathrm{~cm} \times 2 \mathrm{~cm})$ with small obstacles [29], as used before for the CB-/mice $[12,30]$. Slips of the forelimb and hindlimb were counted on the side visible for the experimenter. Values are expressed as numbers of slips per trial for a given day. Data were analyzed using a two-way repeated ANOVA model with between factor genotype (wildtype strains of various genetic backgrounds (see above and $\mathrm{PV}-/-, \mathrm{CB}-/-, \mathrm{PV}-/-\mathrm{CB}-/-$ mice) ) and within factor day (1-5). Differences were considered significant at $P<0.05$. Results are expressed as mean \pm 1 standard error.

\subsection{Rotarod assay}

Mice were tested on a RotaRod device (TSE Systems GmbH, Bad Homburg, Germany) using three different protocols: constant speed $20 \mathrm{rpm}$, accelerating 5-20 rpm and accelerating 10-40 rpm. PV-/- (five females/four males) and control WT (13/5) mice were on the B6 background and the PV-/-CB-/$(12 / 10)$ on the mixed background were compared to one of the mixed background groups $(\mathrm{B} 6 \times 129 \mathrm{P} 2 ; 6 / 13)$. The age of the mice on the starting day (constant speed) ranged from postnatal days P28-P44. The first accelerating protocol started 2 days later and the second one approximately 3 weeks after the start of the rotarod experiments (P49-P57). Each mouse performed up to 12 trials over 2 days on each protocol, with 6 trials per day separated into 2 batches of 3 trials. The mice were allowed to rest for at least $10 \mathrm{~min}$ between trials and the 2 daily batches of trials were separated by at least $2 \mathrm{~h}$. Data was analyzed using the Prism ${ }^{\circledR}$ software (GraphPad, San Diego, USA) and expressed as average latency to fall \pm S.E.M. Statistical analysis was performed using Student's $t$-test, $P<0.05$ was considered statistically significant.

\subsubsection{Locomotor activity monitoring}

Mouse housing and handling was performed as described [31]. Activity records are double-plotted so that each day's cycle activity is plotted both to the right and below that of the previous cycle. We used the Clocklab software (Actimetrics) for wheel running data acquisition and analysis. Locomotor activity counts were assessed from days 5 to 25 with six animals per genotype.

\section{Results}

The genetic background of transgenic or knockout mice is an important factor in behavioral tests [25,32]. Hence, the locomotor tests reported here were first validated with wildtype strains of various genetic backgrounds: B6, 129S5, 129P2 and F1 gen- 
erations $(\mathrm{B} 6 \times 129 \mathrm{P} 2, \mathrm{~B} 6 \times 129 \mathrm{~S} 5)$. The latter two served as models for the $\mathrm{CB}-/-$ and $\mathrm{PV}-/-$ mice, respectively, since they were produced from either R1 or E14 embryonic stem cells, which are derived from either mice resembling 129S5 or from 129P2 mice, respectively [28]. In both cases, targeted ES cells had been injected into $\mathrm{B} 6$ blastocysts and the chimeras mated to $\mathrm{B} 6[11,12]$. The resulting heterozygous mice $(\mathrm{CB}+/-$ or $\mathrm{PV}+/-)$ have a mixed background B6 $\times 129 \mathrm{R} 1$ and B $6 \times 129 \mathrm{P} 2$, respectively, and were used to breed wildtype (+/+) or knockout $(-/-)$ littermates with mixed genetic backgrounds. While for the mixed CB background only littermates from mixed heterozygous pairs were used, in the case of mixed PV animals, a line of mixed $\mathrm{PV}-/-$ mice was generated by systematic randomized matings for more than 10 generations. Additionally, for both null mutations (CB and PV), lines that were backcrossed for 7 (CB) or $8(\mathrm{PV})$ generations to $\mathrm{B} 6$ mice resulting in $\mathrm{B} 6 \mathrm{CB}-/-$ or $\mathrm{B} 6 \mathrm{PV}-/-$ lines were tested.

\subsection{Repeated analysis of locomotor activity and locomotor activity monitoring (wheel running)}

Mice were tested in a box for 18-20 consecutive days for 15 min per trial applying a scheme as described in Section 2 in order to avoid any bias with respect to order of testing or day time. All parameters are based on the crossing of infrared beams (F1-F3) in the box. The measurement of the parameters average activity (AA) and the locomotor inactivity (LIA) revealed significant differences between B6 on one hand and 129S5 and 129P2 on the other hand (Table 1). B6 mice were significantly more active and correspondingly, periods of inactivity were more pronounced in the 129 groups. Interestingly, the locomotor index (LI) was not much different between groups, that is, during periods of activity, the three groups had similar numbers of beam crossings (Table 1) and only in the 129P2 group the LI was smaller. For the assessment of speed characteristic during locomotor activity, the analysis of individual crosscorrelograms (Fig. 2) allowed to determine the average speed for each genetic background or genotype (representing the most frequent time of that subject to cross F1 beam after F3 beam crossing). Additionally, by analysis of the crosscorrelograms, the fastest speed for each genetic background or genotype was calculated. The two parameters related to the speed of movements were significantly affected by the genetic backgrounds. Both the characteristic speed and the fastest speed were lower in the 129 groups compared to the B6 mice. In most parameters analyzed, the $\mathrm{F} 1$ groups were in-between the values measured for the B6 and the 129 groups and again the LI parameter was unaffected and the same as for the pure lines. The percentage of fast movements was somewhat higher in the F1 lines as compared to the parental lines, but the effect was not very pronounced; the 129P2 group had clearly the smallest percentage of fast movements.

Tests of PV $-/-$ or $\mathrm{CB}-/-$ mice were carried out with animals with either a backcrossed B6 background or a mixed background as described above. Since most previously published data on these mice was carried out with animals of mixed genetic background, the number of mice tested in these groups was larger compared to the groups with the backcrossed B6 background. In both genetic backgrounds, PV $-/-$ mice were more active (Table $2 \mathrm{~A}$ ), as evidenced by the increased average activity and the concomitant decreased LIA. Although differences in the $\mathrm{B} 6$ background were less evident, this might also be related to the small number of animals tested. The number of beam crossing during active periods (LI) was not dependent on the presence or absence of PV in both genetic backgrounds.

For a more detailed analysis, the 18-20 days trial session was separated in four blocks (1-4) of 3-6 days (for details, see Section 2). The average activity in the PV-/- group was increased in all four blocks when compared to the WT group, but differences were smaller during block 2 (Fig. 3b). The hallmark of both PV-I- mouse groups with respect to the speed parameters was an increased characteristic speed, whereas all other values were not statistically different between the two groups $(\mathrm{PV}-/-$ and $\mathrm{PV}+/+)$ in both genetic backgrounds (Table $2 \mathrm{~A}$ ). The higher characteristic speed was observed only in blocks 1 and 2, i.e. during the first 8 days of the trial (Fig. 3a; twotailed Mann-Whitney $U$-test, $P<0.05$ ); while at later times the characteristic speed of all four groups was indistinguishable.

For the mixed $\mathrm{CB}$ mice, littermates $(\mathrm{CB}-/-$ and $\mathrm{CB}+/+$ from heterozygous pairings) were tested to further reduce the risk of artifacts due to differences in the genetic background between the two groups. The activity parameters for $\mathrm{CB}-/-$ mice in both genetic backgrounds (mixed and B6) qualitatively showed similar results as for the mice deficient for PV: an increased average activity and concomitantly, a decreased percentage of inactive periods as calculated by the LIA parameter (Table 2B). Furthermore, the temporal pattern of the average activity during the four block periods was similar as found in the PV-Ianimals (Fig. 3b). The characteristic speed was not affected by

Table 1

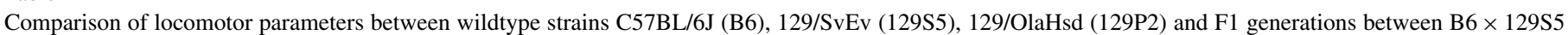
and $\mathrm{B} 6 \times 129 \mathrm{P} 2$

\begin{tabular}{|c|c|c|c|c|c|c|}
\hline & B6 & F1 B6 × 129S5 & $\mathrm{F} 1 \mathrm{~B} 6 \times 129 \mathrm{P} 2$ & 129S5 & $129 \mathrm{P} 2$ & $P$ \\
\hline Number of animals $(n)$ & 10 & 10 & 10 & 7 & 10 & \\
\hline Average activity ${ }^{\mathrm{a}}$ & $0.24 \pm 0.02$ & $0.15 \pm 0.01$ & $0.12 \pm 0.02$ & $0.04 \pm 0.01$ & $0.06 \pm 0.01$ & $<0.0001$ \\
\hline Locomotor inactivity (\%) & $38.0 \pm 2.9$ & $60.2 \pm 2.8$ & $63.9 \pm 4.9$ & $90.4 \pm 1.4$ & $75.8 \pm 4.8$ & $<0.0001$ \\
\hline Locomotor index & $37.8 \pm 1.9$ & $38.2 \pm 2.6$ & $34.4 \pm 2.4$ & $39.6 \pm 4.7$ & $24.8 \pm 1.5$ & 0.0011 \\
\hline Fast movements (\%) & $7.7 \pm 0.6$ & $11.3 \pm 0.9$ & $8.6 \pm 0.8$ & $9.1 \pm 1.7$ & $4.0 \pm 0.6$ & $<0.0001$ \\
\hline Characteristic speed $(\mathrm{mm} / \mathrm{s})$ & $166 \pm 30$ & $131 \pm 20$ & $106 \pm 14$ & $117 \pm 16$ & $84 \pm 10$ & NS \\
\hline Fastest speed (mm/s) & $563 \pm 58$ & $516 \pm 52$ & $420 \pm 49$ & $267 \pm 30$ & $231 \pm 31$ & $<0.0001$ \\
\hline
\end{tabular}

\footnotetext{
a The various parameters are defined in Section 2. A group comparison was carried out by Kruskal-Wallis test.
} 
Table $2 \mathrm{~A}$

Comparison of locomotor parameters between PV $-/-$ and wildtype mice on two genetic backgrounds: a B6 background and a mixed B6 $\times 129 \mathrm{P} 2$ background

\begin{tabular}{|c|c|c|c|c|c|c|c|}
\hline & $\mathrm{B} 6 \mathrm{PV}-/-(n=4)$ & $\mathrm{B} 6 \mathrm{PV}+/+(n=7)$ & $\mathrm{PV}-/-(n=10)$ & $\begin{array}{l}\text { F1 B6 and } \\
129 \mathrm{P} 2(n=10)\end{array}$ & $\begin{array}{l}\mathrm{PV}-/-(\text { all })^{\mathrm{a}} \\
(n=14)\end{array}$ & $\begin{array}{l}\mathrm{PV}+/+(\text { all })^{\mathrm{a}} \\
(n=17)\end{array}$ & \\
\hline Average activity & $0.25 \pm 0.02$ & $0.23 \pm 0.01$ & $0.18 \pm 0.01$ & $0.12 \pm 0.02$ & $141 \pm 10$ & $100 \pm 10$ & $* *$ \\
\hline Locomotor inactivity (\%) & $43.0 \pm 1.4$ & $53.7 \pm 3.6$ & $49.6 \pm 4.2$ & $63.9 \pm 4.9$ & $78 \pm 5$ & $100 \pm 5$ & $* *$ \\
\hline Fast movements (\%) & $10.3 \pm 0.7$ & $12.7 \pm 1.2$ & $10.7 \pm 0.4$ & $8.6 \pm 0.8$ & $112 \pm 6$ & $100 \pm 7$ & NS \\
\hline Characteristic speed $(\mathrm{mm} / \mathrm{s})$ & $81 \pm 15$ & $64 \pm 2$ & $143 \pm 16$ & $106 \pm 14$ & $132 \pm 12$ & $100 \pm 8$ & \\
\hline Fastest speed $(\mathrm{mm} / \mathrm{s})$ & $300 \pm 41$ & $382 \pm 102$ & $487 \pm 21$ & $420 \pm 49$ & $105 \pm 6$ & $100 \pm 12$ & NS \\
\hline
\end{tabular}

We tested whether the difference between the two "all" groups was equal to zero (chi-square test). $P$-values were classified as ${ }^{* *} P<0.005,{ }^{*} P<0.05$ and NS: $P>0.05$; not significant.

a Since the parameters in PV+/+ mice are significantly different in the mixed and the B6 background (Table 1), the wildtype values of both genetic backgrounds were set to $100 \% \mathrm{PV}+/+$ (all), and the corresponding PV $-/-$ groups $\mathrm{PV}-/-$ (all) calculated according to the two wildtype groups.
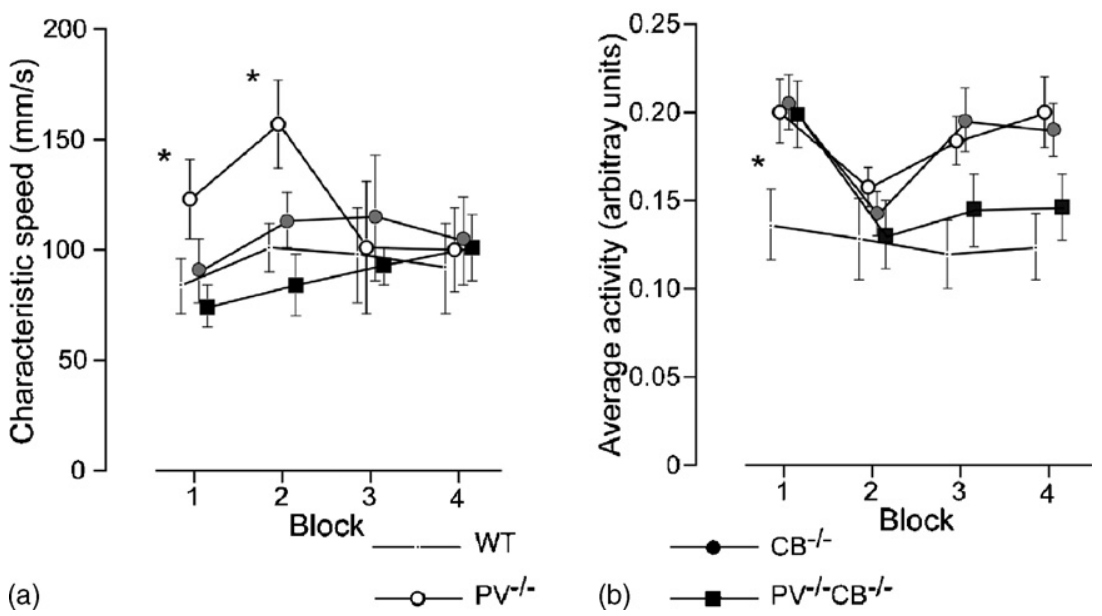

Fig. 3. Analysis of the characteristic speed (a) and the average activity (b). Various genotypes of mice, $\mathrm{PV}-/-(n=10), \mathrm{CB}-/-(n=10), \mathrm{PV}-/-\mathrm{CB}-/-(n=11)$ and WT controls $(n=10)$ were tested in a box for 18-20 days. The entire period was divided into four blocks of 3-5 days to observe changes in the parameters "characteristic speed" and "average activity" during the four time periods; blocks $1-4$ correspond to data pooled from days 1 to 3,4 to 8,9 to 13 and $14-18$, respectively; values are mean \pm S.E.M. (a) The characteristic speed of PV-/- mice was significantly increased during blocks 1 and 2 . *: two-tailed Mann-Whitney $U$-test, $P<0.05$, statistically significant vs. WT and $\mathrm{PV}-/-\mathrm{CB}-/-$ in block 1 and vs. all other groups in block 2 . (b) The average activity in block 1 was higher in all mutant genotypes when compared to the WT group $\left({ }^{*} P<0.05\right)$.

the absence of $\mathrm{CB}-/-$ in both backgrounds, but the percentage of fast movements was slightly lower in both $\mathrm{CB}-/-$ groups (more prominent in mice with a B6 background) than in wildtype controls (Table 2B).

$\mathrm{PV}-/-\mathrm{CB}-/-$ mice have a relatively complicated genetic background $(\mathrm{B} 6 \times 129 \mathrm{R} 1 \times 129 \mathrm{P} 2)$ and since corresponding wildtype littermates were not available, we took the ensemble of the F1 groups $(\mathrm{B} 6 \times 129 \mathrm{~S} 5$, B6 $\times 129 \mathrm{P} 2 ; n=10$ for both groups) as the corresponding control group (for details, see Section 2). All activity parameters were essentially unchanged in the $\mathrm{PV}-/-\mathrm{CB}-/-$ mice (AA, LIA), the only difference was a slightly lower locomotor index (Table 2C), indicating that mice deficient for both proteins tend to be less mobile during periods of locomotor activity (two-tailed Kruskal-Wallis test, $P<0.01$ ). Analysis of the average activity during the four blocks revealed the activity to be higher in block 1 (similar

Table 2B

Comparison of locomotor parameters between $\mathrm{CB}-/-$ and wildtype mice on a mixed B6 $\times 129 \mathrm{~S} 5$ background and on a B6 background

\begin{tabular}{|c|c|c|c|c|c|c|c|}
\hline & $\mathrm{CB}-/-(n=10)$ & $\begin{array}{l}\text { F1 B6 and } \\
129 \mathrm{~S} 5(n=10)\end{array}$ & $\mathrm{B} 6 \mathrm{CB}-/-(n=3)$ & $\mathrm{B} 6 \mathrm{CB}+/+(n=5)$ & $\begin{array}{l}\mathrm{CB}-1-(\text { all })^{\mathrm{a}} \\
(n=13)\end{array}$ & $\begin{array}{l}\mathrm{CB}+/+(\text { all })^{\mathrm{a}} \\
(n=15)\end{array}$ & \\
\hline Average activity & $0.18 \pm 0.01$ & $0.15 \pm 0.01$ & $0.18 \pm 0.08$ & $0.15 \pm 0.05$ & $119 \pm 9$ & $100 \pm 6$ & N \\
\hline Locomotor index & $35.8 \pm 1.3$ & $38.2 \pm 2.6$ & $38.0 \pm 5.5$ & $38.8 \pm 3.5$ & $95 \pm 3$ & $100 \pm 5$ & NS \\
\hline Fast movements (\%) & $9.6 \pm 0.4$ & $11.3 \pm 0.9$ & $7.4 \pm 1.3$ & $11.5 \pm 0.6$ & $80 \pm 5$ & $100 \pm 6$ & \\
\hline Characteristic speed $(\mathrm{mm} / \mathrm{s})$ & $154 \pm 13$ & $131 \pm 20$ & $115 \pm 54$ & $93 \pm 37$ & $119 \pm 10$ & $100 \pm 12$ & NS \\
\hline Fastest speed $(\mathrm{mm} / \mathrm{s})$ & $551 \pm 71$ & $516 \pm 52$ & $426 \pm 70$ & $436 \pm 117$ & $105 \pm 11$ & $100 \pm 8$ & NS \\
\hline
\end{tabular}

$P$-values were classified as ${ }^{* *} P<0.005,{ }^{*} P<0.01$ and NS: $P>0.05$; not significant.

${ }^{a}$ For details, see text in Table 2A. 
Table 2C

Comparison of locomotor parameters between $\mathrm{PV}-/-\mathrm{CB}-/-$ and wildtype mice on a mixed background

\begin{tabular}{|c|c|c|c|}
\hline & $\mathrm{PV}-/-\mathrm{CB}-/-(n=11)$ & $\mathrm{PV}+/+\mathrm{CB}+/+^{\mathrm{a}}(n=20)$ & \\
\hline Average activity & $0.15 \pm 0.02$ & $0.14 \pm 0.01$ & NS \\
\hline Locomotor inactivity (\%) & $53.7 \pm 5.2$ & $62.0 \pm 2.8$ & NS \\
\hline Locomotor index & $31.3 \pm 1.2$ & $36.3 \pm 1.8$ & $*$ \\
\hline Fast movements (\%) & $4.9 \pm 0.9$ & $9.9 \pm 0.7$ & $* *$ \\
\hline Characteristic speed $(\mathrm{mm} / \mathrm{s})$ & $97 \pm 6$ & $118 \pm 12$ & NS \\
\hline Fastest speed $(\mathrm{mm} / \mathrm{s})$ & $347 \pm 20$ & $468 \pm 37$ & $* *$ \\
\hline
\end{tabular}

Statistically significant differences were calculated by chi-square test analysis. $P$-values were classified as ${ }^{* *} P<0.001,{ }^{*} P<0.01$ and NS: $P>0.05$; not significant.

${ }^{a}$ For the details on the exact genetic background of the two groups, see Section 2.

values as in the $\mathrm{PV}-1-$ and $\mathrm{CB}-1-$ groups), but in blocks $2-4$ activity values were not different from the WT group (Fig. 3b). In the PV-/-CB-/- group, the most striking differences were observed in the significantly reduced percentage of fast movements $(9.9 \pm 0.7$ versus $4.9 \pm 0.9)$ and the decreased fastest speed $(468 \pm 37 \mathrm{~mm} / \mathrm{s}$ versus $347 \pm 20 \mathrm{~mm} / \mathrm{s}$; twotailed Kruskal-Wallis test, $P<0.0001)$. Fast movements were decreased during all four blocks and no significant differences existed between blocks; also in all other groups tested the percentage of fast movements was relatively constant during all four blocks (not shown). Interestingly, no significant changes were observed in the characteristic speed, although values were generally slightly lower than in the other groups (Table 2C and Fig. 3a).

In order to preclude that the observed changes related to locomotor activity reported above were the result of a generally altered diurnal behavior, mice were tested in a wheel-running assay. Animals were kept individually on a $12 \mathrm{~h} / 12 \mathrm{~h} \mathrm{light/dark}$ cycle and their wheel-running activity was monitored continuously for 25 days. We selected a wildtype control group $(\mathrm{B} 6 \times 129 \mathrm{P} 2)$ and the double knockout mutants $(\mathrm{PV}-/-\mathrm{CB}-/-)$, since both proteins are expressed in specific neurons in the suprachiasmatic nucleus $(\mathrm{SCN})$ of the hypothalamus [33], a region considered essential for the control of endogenous circadian rhythms and entrainment to the environment. Two representative actograms from a WT and a $\mathrm{PV}-/-\mathrm{CB}-/-$ mouse are shown in Fig. 4 . The activity pattern is essentially the same, i.e. strong activity at the onset of the dark cycle subsiding towards the end and very little activity during the light cycle. The overall activity expressed as total wheel revolutions/min was calculated for the period between days 5 and 25 , the first 4 days were considered as training period. The value for the WT group was $6.8 \pm 2 \mathrm{rpm}$ (mean \pm S.E.M.; $n=6$ ) and for the $\mathrm{PV}-/-\mathrm{CB}-/-$ group slightly lower, $5.4 \pm 0.8 \mathrm{rpm}$ (mean \pm S.E.M.; $n=6 ; P>0.5, t$-test). Thus, diurnal activity is not significantly different between the null-mutant and the control group indicating that the differences presented above are genotypic differences not related to diurnal activity.

In summary, each genotype is characterized by a specific set of affected parameters when compared to their respective control group as summarized in Table 4. The sole absence of PV is manifested in an increased characteristic speed during the first 8 days of the experiment that drops in the second period to values recorded in the other groups. Deficiency in $\mathrm{CB}$ alone slightly decreases the percentage of fast movements, but otherwise these mice show the least differences when compared to the WT group. If both proteins are absent in $\mathrm{PV}-/-\mathrm{CB}-/-$ mice, the percentage fast movements drops by approximately $50 \%$ compared to the corresponding WT group. Additionally the fastest speed is strongly reduced (Table 2C). This is in line with the previously reported impairment in motor coordination seen in $\mathrm{CB}-/-$ mice $[12,30]$.
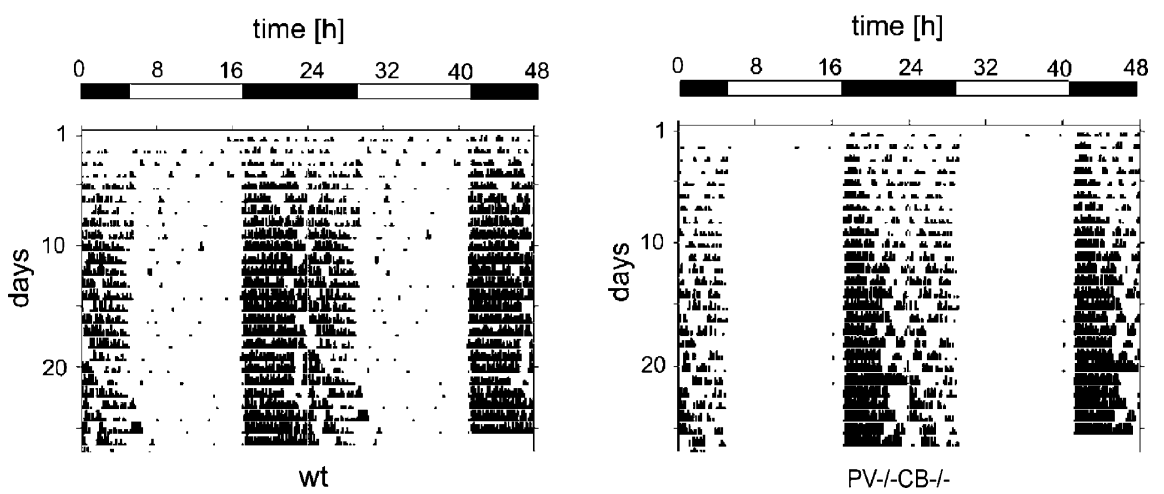

Fig. 4. Representative actograms of a WT and PV-/-CB-/- mouse in the wheel-running assay. The wheel-running activity of individually housed mice was recorded for 25 days. It is plotted by aligning two consecutive days horizontally. Black vertical bars plotted side-by-side represent the activity (number of wheel revolutions). The height of each vertical bar indicates the accumulated number of wheel revolutions. The white and black bar at the top of the scheme depicts light (12 h) and darkness (12 h), respectively. 
Table 3

Locomotor parameters determined in the Tru scan box

\begin{tabular}{|c|c|c|c|c|c|c|c|c|}
\hline & Move number & Rest time & Total distance & Marginal distance & Marginal time & Center distance & Center time & Vertical breaks \\
\hline $\mathrm{B} 6(n=8)$ & $7.78 \pm 1.02$ & $11.50 \pm 2.16$ & $187.47 \pm 26.93$ & & & $33.59 \pm 13.51$ & $17.03 \pm 6.82$ & $=0.77$ \\
\hline $129 S 5(n=14)$ & $6.97 \pm 1.79$ & $36.90 \pm 10.06$ & $43.17 \pm 28.07$ & $35.17 \pm 19.90$ & $58.10 \pm 3.70$ & $2.46 \pm 5.20$ & $1.90 \pm 3.70$ & $0.75 \pm 0.76$ \\
\hline $\begin{array}{l}\text { F1 B6 and 129P2 } \\
\quad(n=20)\end{array}$ & $9.13 \pm 1.09$ & $21.54 \pm 4.51$ & $104.79 \pm 27.62$ & $64.72 \pm 12.45$ & $51.88 \pm 4.04$ & $14.08 \pm 7.12$ & $8.13 \pm 4.04$ & $3.60 \pm 1.56$ \\
\hline $\mathrm{CB}+/+(n=8)$ & $8.76 \pm 1.32$ & & & & & & & \pm 2.61 \\
\hline$P V-/-(n=12)$ & $8.79 \pm 1.22$ & $21.04 \pm 5.60$ & $101.72 \pm 46.82$ & $65.91 \pm 17.63$ & & $10.50 \pm 12.97$ & $6.83 \pm 7.12$ & $2.83 \pm 1.82$ \\
\hline $\mathrm{CB}-1-(n=8)$ & $8.99 \pm 1.09$ & $15.66 \pm 4.13$ & $120.42 \pm 43.45$ & $65.52 \pm 26.42$ & $43.84 \pm 6.38$ & $22.33 \pm 7.75$ & $16.16 \pm 6.38$ & $4.84 \pm 2.00$ \\
\hline $\mathrm{PV}-/-\mathrm{CB}-/-$ & $9.19 \pm 0.80$ & $21.71 \pm 6.83$ & $89.79 \pm 36.40$ & $49.03 \pm 12.63$ & $48.93 \pm 7.71$ & $18.07 \pm 15.30$ & $11.07 \pm 7.71$ & $2.48 \pm 1.59$ \\
\hline
\end{tabular}

$(n=12)$

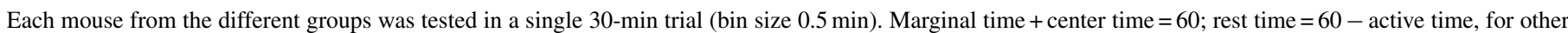
details, see Section 2.

\subsection{Spontaneous activity exploring an unfamiliar environment}

Mice were tested in this "classical" assay in a random order in a commercial activity cage for $30 \mathrm{~min}$ one time. Wildtype mice with different genetic backgrounds serving as controls for the knockout mice were tested. Since in the previous experiment (repeated analysis of locomotor activity), no significant differences between the F1 B $6 \times 129$ S5 and the F1 B $6 \times 129 \mathrm{P} 2$ groups (Table 1) were observed, the F1 B6 × 129P2 mice served as controls for both $\mathrm{PV}-/-$ and $\mathrm{CB}-/-$ mice and also only two pure strains (B6 and 129S5) were tested. The move number (Table 3 ) is the equivalent of the average activity (AA) parameter in the first experiment. Since the IR beams are more closely spaced in the commercial box, the parameters move time, rest time (similar to LIA) and total distance were recorded. Furthermore, the presence of beams in the $X$ - and $Y$-axis additionally allowed to monitor the time spent and the distance covered in the center of the cage (center distance, center time) versus these parameters recorded along the walls of the cage (marginal distance, marginal time). Finally the beam in the $Z$-axis allowed the measurement of vertical breaks (rearing). All parameters (with the exception of move number) were significantly different between B6 and 129S5 mice (Table 3). The rest time was lower in B6 mice, they spent significantly more time in the center of the box and also the total distance covered during the 30-min trial was longer. Additionally, rearing in B6 mice occurred significantly more often than in the 129S5 group. In almost all of the parameters tested, the values for the $\mathrm{F} 1$ generation with a mixed background B $6 \times 129 \mathrm{P} 2$ were almost identical to the mean value between B6 and 129S5 (Table 3), that is, neither background is dominant with respect to these parameters.

When comparing mice lacking $\mathrm{CB}$, PV or both with the corresponding control groups $(\mathrm{CB}+/+$ and $\mathrm{B} 6 \times 129 \mathrm{P} 2$, respectively); no statistically significant differences were observed by ANOVA single factor analysis $(P>0.05$ for all parameters). A direct comparison between the $\mathrm{PV}-/-$ and $\mathrm{CB}-/-$ groups revealed an increased center time for $\mathrm{CB}-/-$ mice compared to $\mathrm{PV}-/-$ mice $(P=0.0156)$. Additionally, the number of vertical breaks was somewhat higher in $\mathrm{CB}-/-$ than in $\mathrm{PV}-/-$ mice $(P=0.0472)$. The same effect was also seen when com- paring $\mathrm{CB}-/-$ with $\mathrm{PV}-/-\mathrm{CB}-/-$ mice $(P=0.0466)$. If all mice analyzed were pooled in two groups only, i.e. mice having PV $(\mathrm{F} 1 \mathrm{~B} 6 \times 129 \mathrm{P} 2, \mathrm{CB}+/+, \mathrm{CB}-/-)$ or deficient for PV $(\mathrm{PV}-/-, \mathrm{PV}-/-\mathrm{CB}-/-)$ the rearing values were $4.10 \pm 1.96$ versus $2.64 \pm 1.63$, respectively. One-way ANOVA $(P<0.0071)$ revealed this parameter to be statistically different between the two groups and indicates that the lack of PV reduces the number of vertical breaks, which is considered as factor measuring exploratory activity.

\subsection{Testing of motor coordination in the runway assay}

$\mathrm{CB}-/$ - mice manifest impairment in motor coordination including deficits in the runway assay [12] that can be attributed to the absence of CB in Purkinje cells [30]. Since PV is also abundantly expressed in Purkinje cells and molecular layer interneurons, $\mathrm{PV}-/-$ and mice deficient for both $\mathrm{CB}$ and $\mathrm{PV}$ were tested in the same runway assay under the same experimental conditions. The assays with the different genetic backgrounds (B6, 129S5, F1 B6 × 129S5, congenic B6.129R1) revealed similar findings as previously reported for the wildtype littermates from the $\mathrm{CB}-/-$ mice [12]: differences between the various wildtype strains are minor with respect to both number of slips and the learning rate during the 5-day period when compared to the large differences in the $\mathrm{CB}-/-$ mice (Fig. 5A). Since the putative differences were much smaller in the PV-/- group, a detailed analysis of the WT strains was carried out beforehand (Fig. 5B). Differences in both the number of slips and the learning rate were observed in the four WT groups. The poorest performers were the B6 mice, while the number of slips was lowest in the F1 B $6 \times 129$ S5 group. The main effect of group is reproduced by one-way factorial ANOVA on average slip counts, with post hoc analysis revealing a significant difference between the groups B6 and F1 B6 $\times 129$ S5 $(P=0.0026)$. The main effect of group is reproduced by the non-parametric Kruskal-Wallis test $(P=0.0165)$. Also the learning rates were most different between B6 and F1 B6 $\times 129$ S5 factorial one-way ANOVA: $P<0.05$; post hoc analysis $\mathrm{B} 6$ and $\mathrm{F} 1 \mathrm{~B} 6 \times 129 \mathrm{~S} 5$; $P=0.0128$; Kruskal-Wallis test $(P=0.0443)$. In summary, the line plot indicates that B6 mice perform more poorly than the other WT strains, but compensate this by a steeper learning rate. 

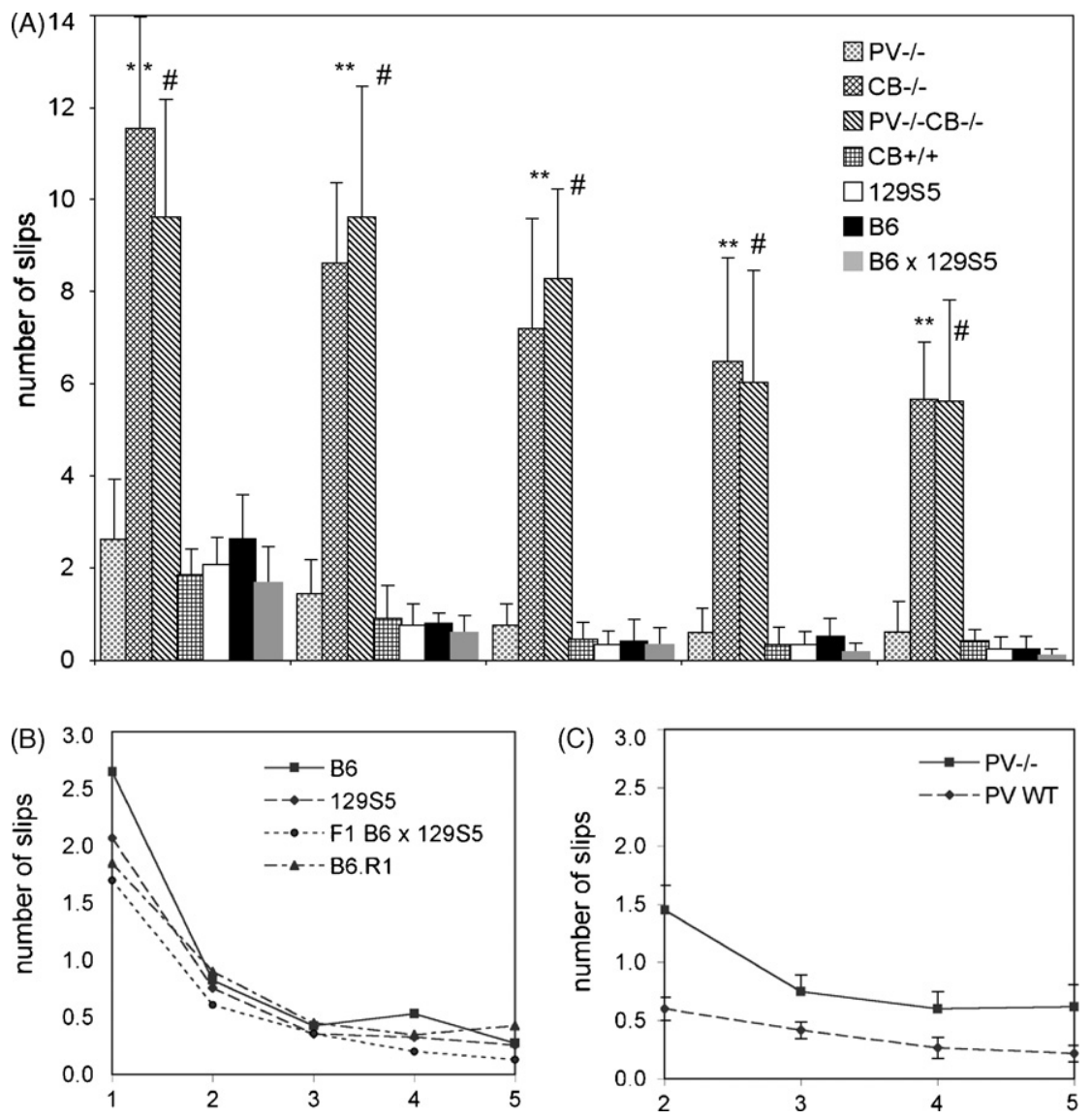

Fig. 5. Motor coordination test. (A) Runway assay with wildtype strains of different genetic backgrounds (B6, 129S5, F1 B6 × 129S5, congenic B6.129R1; CB+/+) and mutant mice for $\mathrm{PV}(\mathrm{PV}-/-), \mathrm{CB}(\mathrm{CB}-/-)$ or both proteins $(\mathrm{PV}-/-\mathrm{CB}-/-)$. Values are shown as mean $\pm \mathrm{SD}$. ${ }^{*} P<0.02$ vs. F1 B6 $\times 129 \mathrm{~S} 5 ; P<0.002$ vs. $\mathrm{CB}+/+$ (both $\mathrm{CB}-/-$ and $\mathrm{CB}+/+$ are littermates with congenic B6.129R1); ${ }^{n}$ n.s. vs. $\mathrm{CB}-/-$. (B) Comparison of the four wildtype strains as in (A) from days 1 to 5 : no significant differences between the groups are observed from day 2 on. (C) Comparison of all pooled wildtype strains (PV WT) with the PV-/- mice from days 2 to 5 (mean \pm S.E.M.): performance in the PV $-/$ - group is poorer than in the WT group (group: $P=0.0027$; interaction: $P=0.0466$ ).

On the other hand, the four groups $\mathrm{PV}-1-, \mathrm{CB}-/-$, double mutants and WT (the F1 B6 $\times 129$ S5 was selected as representative WT strain) differed clearly both with respect to overall performance and learning rate in the runway test (Fig. 5A; $P<0.0001$ for the parameters genotype, day and interaction genotype-day). CB-/- were overall massively impaired compared to WT mice despite a slightly steeper learning rate (partial ANOVA $\mathrm{CB}-1-$ versus WT: $P<0.0001$ for the parameters genotype, day and interaction genotype-day). $\mathrm{PV}-/-$ showed a significantly better performance than $\mathrm{CB}-/-$, yet compared to WT their overall performance was still reduced (partial ANOVA PV $-1-$ versus WT (days 2-5): genotype $P<0.005$, day $P<0.0001$, interaction $P=0.0466$ ). For the comparison PV $-/-$ versus WT, only days $2-5$ were analyzed based on the results from the different WT strains that differences in performance in the WT groups are mainly manifested on the first day (Fig. 5B; interaction (days 2-5) corroborated by two-way repeated ANOVA $P=0.7828$ ). Results for the $\mathrm{PV}-/-\mathrm{CB}-1-$ mice were essentially the same as for the $\mathrm{CB}-/-$ animals and suggest that $\mathrm{CB}$ deficit is the major factor contributing to the observed motor coordination impairment in $\mathrm{PV}-/-\mathrm{CB}-/-$, since no synergistic effect of combined PV- and CB-deficiency could be detected.

\subsection{Rotarod assay}

The putative roles of $\mathrm{CB}$ and $\mathrm{PV}$ were assessed in a second Purkinje-cell-dependent task, the Rotarod assay. We tested two groups of knockout mice: the PV-/- mice that present a very minor effect in the runway assay and the $\mathrm{PV}-/-\mathrm{CB}-/-$ mice that showed a pronounced one. Interestingly, the PV-Imice performed better during the first task (constant $20 \mathrm{rpm}$ ) compared to the WT group, while for the more difficult tasks (accelerating rod 5-20 and 10-40 rpm) there were no differences between $\mathrm{PV}-1-$ and WT groups (Fig. 6). When analyzing days 1 and 2 at constant speed separately, the differences in performance were significant only at day 1 , when PV-/- stayed on for longer periods (71.3 $\pm 7.1 \mathrm{~s}$; mean \pm S.E.M.) than WT mice $(47.5 \pm 4.0 \mathrm{~s} ; P<0.005)$. Qualitatively, WT mice apparently searched for a way to "escape" the test by turning around whilst on the rotarod and walking backwards, sometimes numerous times per trial, which often resulted in falling down, while PV $-/-$ consistently walked in the direction (forward) as they were initially placed. Quantitatively, this effect was analyzed in the PV $-/-\mathrm{CB}-/-$ and the corresponding WT group $(\mathrm{B} 6 \times 129 \mathrm{P} 2)$ during the $10-40 \mathrm{rpm}$ protocol and the results are expressed as turns per mouse per minute on the rotarod device. 
Rotarod, constant 20 rpm

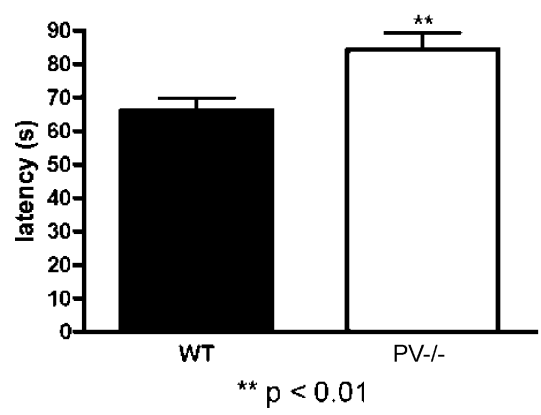

Rotarod - constant 20 rpm

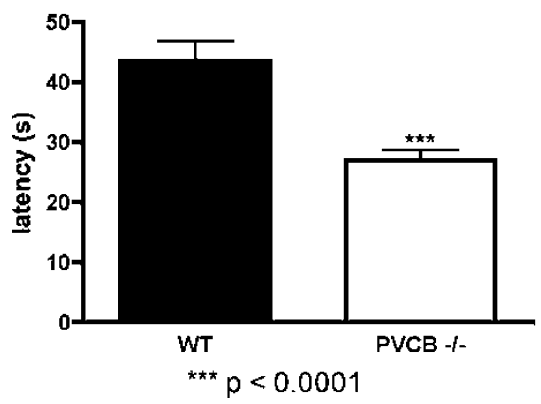

Rotarod 5 - 20 rpm

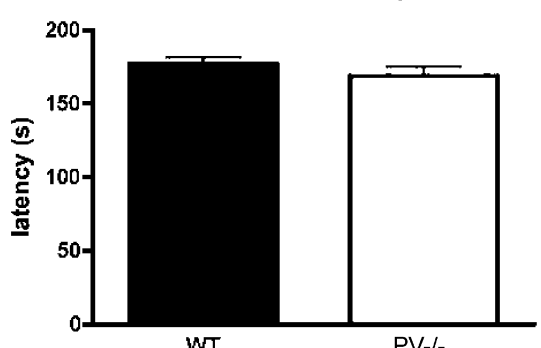

WT

Rotarod 5 - 20 rpm

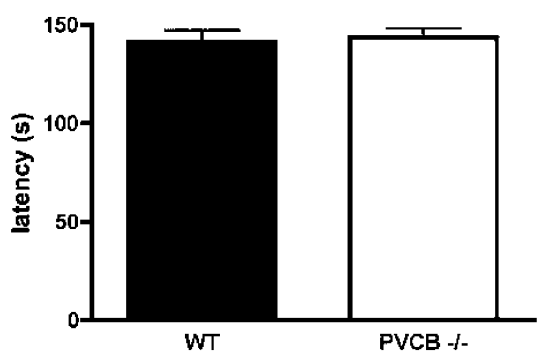

Rotarod 10 - 40 rpm

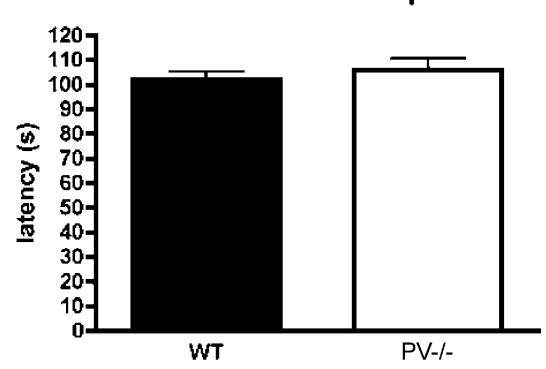

Rotarod $10-40$ rpm

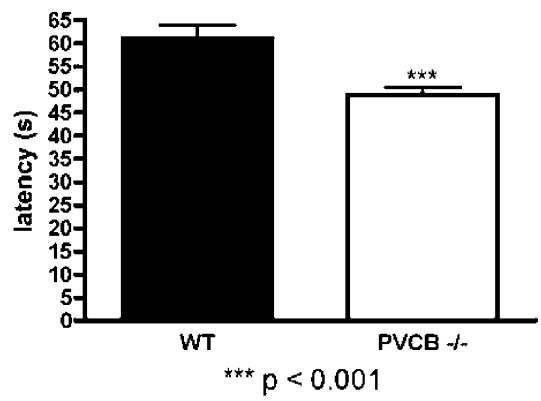

Fig. 6. Motor impairment in CaBP knockout mice analyzed on the rotarod. Three different protocols were used: constant speed (20 rpm), accelerating speed (5-20 and 10-40 rpm), for details, see Section 2. Single knockout mice for PV (PV-/-) and double KO mice (PV-/-CB-/-) were compared to their respective WT groups. Note the different scales on the $y$-axis (latency to fall) in the different tests.

On average, WT mice turned around $1.3 \pm 0.5 \mathrm{~min}^{-1}$, while the double mutants never turned during the investigated period.

The PV-/-CB-/- mice had some difficulties learning the rotarod task (worse performance in the first test $(20 \mathrm{rpm}$ constant)), but at later times were equally good on the accelerating rod (5-20 rpm). As the difficulty of the task increased (10-40 rpm), the deficits in motor coordination were again manifested. Globally, the results of the rotarod and the runway give the same picture: minor changes in $\mathrm{PV}-/-$, major changes when also $\mathrm{CB}$ is missing confirming the previous hypothesis that $\mathrm{CB}$ is the main determinant for the observed deficits in motor coordination.

\section{Discussion}

Elimination of functional genes is assumed to produce a phenotype that might give clues about the specific physiological function(s) of the deleted protein. In case of proteins expressed in the CNS the phenotypic changes might be also manifested at the behavioral level. As a starting point, testing of spontaneous locomotor activity either in a novel environment or repeated recordings in a familiar environment were carried out with mice deficient for PV and CB. Since the available mice have a rather complex genetic background and since the test of "repeated locomotor activity" had not been previously validated with different wildtype strains, several pure (B6, 129S5, 129P2) or "mixed" $(\mathrm{F} 1$ of B $6 \times 129 \mathrm{~S} 5, \mathrm{~B} 6 \times 129 \mathrm{P} 2)$ wildtype strains were analyzed beforehand. As reported before [25,32,34], 129 mice were significantly less active than B6 animals shown by the decreased average activity (AA) and the smaller total distance traveled. The exploratory activity of 129 mice was diminished: the center time and distance were decreased significantly and less rearing was observed as reported before [25]. The activity effects are very robust and seen in both assays, which were carried out in two different laboratories (Martinsried, Germany and Lausanne, Switzerland). While in some assays many different tests were performed with a number of "pure" genetic strains (e.g. [32]), much less information is available on F1 generations of pure strains [25,34]. In the latter report the authors point out that behavioral scores of F1 hybrid mice cannot be easily predicted from the knowledge of the parental strains and that for each hybrid strain the parameters for each behavioral test need to be determined. Since most of the common strains of knockout mice have been generated on a mixed B $6 \times 129$ backgrounds, the characteristics of such mice were investigated in detail. Either congenic lines or F1 generations derived from pure B6 and 129 lines were investigated. In all tested parameters that were significantly different between B6 and 129 mice, the values of the F1 generations as well as the congenic line $(\mathrm{CB}+/+$; $\mathrm{B} 6 \times 129 \mathrm{R} 1)$ were almost identical to the average of the values for the pure strains. This was surprising, since in other F1 hybrids and behavioral tests (e.g. Y-maze rearing, tactile startle), such a simple correlation does not hold true [34]. As calculated for the parameters average activity, total distance, marginal distance, marginal time, fastest speed and vertical breaks (rearing) the arithmetical average was generally well within the S.E.M.-interval of these parameters (not shown). In addition, the S.E.M. values for the B 6129 backgrounds were not systematically larger 
than these values for the pure strains. That is, even if differences between wildtype and genetically modified mice with a mixed genetic background lay within the boundaries set by the B6 and 129 backgrounds, statistically significant differences can be attributed to the genetic manipulations. Therefore, the comparison of data obtained with CaBP-deficient mice with that of genetically matched controls allowed us to assign distinct differences in these assays to the absence of a particular $\mathrm{CaBP}$.

It has been shown previously that PV- and CB-expressing neurons are normal at the gross histological level in $\mathrm{PV}-/-$ and $\mathrm{CB}-/-$ mice with no apparent up-regulation of other CaBPs $[11,12]$ supporting the original hypothesis that PV and $\mathrm{CB}$ are not essential for the basic properties of particular subtypes of cells [6]. Furthermore, these mice were normal and indistinguishable from the other littermates with respect to development, physical activity and behavior under standard housing conditions. Closer inspection of $\mathrm{PV}-/-, \mathrm{CB}-/-$ and $\mathrm{PV}-/-\mathrm{CB}-/-$ mice revealed significant functional alterations at cortical, hippocampal and cerebellar levels (for a review on the cerebellum, see [4]). Electrophysiological recordings of cortical, hippocampal and cerebellar sites in $\mathrm{PV}-/-$ mice showed important modifications in the function of the inhibitory systems [14,16,17,35]. Moreover, direct evidence that endogenous CaBPs play an important role in the cerebellar physiology was provided by behavioral analysis investigated in $\mathrm{CB}-1-$ mice and more recently in mice lacking the closely related protein calretinin. These mice revealed motor coordination impairment associated with alterations in $\mathrm{Ca}^{2+}$-transients and firing behavior of Purkinje cells [12,36].

It is interesting to note that deficiency in either one (PV, CB) or both of the CaBPs had no significant effect on the locomotor activity tested in a novel environment for only $30 \mathrm{~min}$. On the other hand, detailed analysis of the activity during repetitive sessions in an environment without any external disturbances revealed distinct differences between all three genotypes (Table 4). It is important to stress that the differences between $\mathrm{CaBP}-$ deficient mice and control animals were robust and practi-

Table 4

Summary of parameters related to locomotion and Purkinje cell electrophysiology ${ }^{\mathrm{a}}$ in mice deficient for $\mathrm{PV}, \mathrm{CB}$ or both

\begin{tabular}{|c|c|c|c|}
\hline & $\mathrm{PV}-1-$ & $\mathrm{CB}-1-$ & $\mathrm{PV}-/-\mathrm{CB}-1-$ \\
\hline Average activity & $\uparrow \uparrow^{* * *}$ & $\uparrow^{*}$ & - \\
\hline Locomotor inactivity & $\Downarrow^{* *}$ & $\Downarrow^{*}$ & - \\
\hline Locomotor index & - & - & $\Downarrow$ \\
\hline Characteristic speed & $\uparrow^{*}$ & - & - \\
\hline Fastest speed & - & - & $\Downarrow \Downarrow^{* *}$ \\
\hline$\%$ of fast movements & - & $\Downarrow \Downarrow^{* *}$ & $\Downarrow \Downarrow^{* *}$ \\
\hline Spontaneous activity & - & - & - \\
\hline Vertical breaks & $\Downarrow^{\#}$ & - & $\Downarrow^{\#}$ \\
\hline Motor coord. impairment & $\Downarrow^{*}$ & $\Downarrow \Downarrow^{* *}$ & $\Downarrow \Downarrow^{* *}$ \\
\hline Simple spike firing rate ${ }^{\mathrm{a}}$ & $\uparrow$ & $\uparrow \uparrow$ & $\uparrow \uparrow$ \\
\hline Complex spike (CS) duration ${ }^{\mathrm{a}}$ & $\Downarrow$ & $\Downarrow \Downarrow$ & $\Downarrow \Downarrow$ \\
\hline Spike pause after $\mathrm{CS}^{\mathrm{a}}$ & $\Downarrow$ & $\Downarrow \Downarrow$ & $\Downarrow \Downarrow$ \\
\hline
\end{tabular}

(-) Unchanged; $(\uparrow)$ increased; $(\Downarrow)$ decreased. Two symbols represent strong effects. $P$-values were classified as ${ }^{* *} P<0.01 ;{ }^{*} P<0.05$; ${ }^{\#} 0.05>P>0.1$, tendency.

${ }^{a}$ Results from Ref. [35]. cal identical results were obtained in both, the mixed $($ B6 $\times 129)$ or the backcrossed "pure" B6 genetic backgrounds. This strongly favors the alterations being due to the elimination of the functional $\mathrm{CaBP}$ genes as opposed to effects resulting from different genetic backgrounds.

Analysis of the parameters related to the speed of movements showed that the characteristic speed was increased in $\mathrm{PV}-1-$ mice during the first 8 days of testing (blocks 1 and 2). The exact nature of this effect is currently unknown, but it might be correlated with the decreased exploratory activity (diminished rearing). Analysis of locomotion in the open-field assay revealed an increased microlinearity of movements, i.e. $\mathrm{PV}-/$ - tended to move in one direction for longer periods and larger distances before stopping or turning, likely yielding a higher characteristic speed, but a more detailed analysis is in progress (P. Gregory, in preparation). In mice lacking $\mathrm{CB}$ ( $\mathrm{CB}-/-$ and $\mathrm{PV}-/-\mathrm{CB}-/-$ ) the fastest speed was lower than in the groups expressing this protein. It seems that this parameter is strongly correlated with the motor coordination deficits observed in CB-deficient and also in double knockout mice ([12] and this study). The impaired motor coordination in $\mathrm{CB}-1-$ mice can be selectively attributed to the elimination of $\mathrm{CB}$ from Purkinje cells, since Purkinje cell-specific CB knockout mice display marked permanent deficits of motor coordination [30] in the runway assay similar to mice where $\mathrm{CB}$ expression is globally deleted. Also our results of the rotarod assay point in the direction that the absence of $\mathrm{CB}$ is the main factor for the motor impairment, while the effect of PV-deficiency is rather subtle and beyond detection in most assays. As previously demonstrated for the absence of CB and CR [37], also elimination of PV leads to changes in the firing properties of Purkinje cells: an increase in the simple spike firing rate (SS), a shortening of the complex spike duration (CSd), and a shortening of the spike pause after a complex spike (CSp) [35]. Interestingly, in animals lacking $\mathrm{CB}$ ( $\mathrm{CB}-/-$ and double-KO), the differences of the above parameters (SS, CSd and CSp) compared to WT are much more pronounced than in the $\mathrm{PV}-/-$ mice, but are not significantly different in $\mathrm{CB}-/-$ and double-KO mice. This correlates well the graded differences in motor coordination impairment: $\mathrm{PV}-/-\mathrm{CB}-/-\approx \mathrm{CB}-/-\gg \mathrm{PV}-/->\mathrm{WT}$. In animals deficient for either one of the CaBPs (CR, CB, PV) or the combinations $\mathrm{CB} / \mathrm{CR}$ and $\mathrm{PV} / \mathrm{CB}$, in addition to altered $\mathrm{PC}$ firing the concomitant emergence of $160-\mathrm{Hz}$ oscillations in the cerebellum of alert mice has been observed [35,37]. Such oscillations are not encountered in WT and it was proposed that these oscillations would impair the normal functioning of the cerebellar circuitry possibly causing the motor coordination impairment. The importance of CR in cerebellar granule cells was demonstrated by a granule cell-specific $\mathrm{CR}$ rescue, where transgenic mice expressing $\mathrm{CR}$ under the control of the $\mathrm{GABA}_{\mathrm{A}}$ receptor alpha6 were crossed with $\mathrm{CR}-/-$ mice [38]. In these mice granule cell excitability and Purkinje cell firing behavior in awake animals was normal and no high-frequency oscillations were observed. Consequently, motor coordination in the runway assay was as in WT mice indicating that the fine-tuning of $\mathrm{Ca}^{2+}$ signals in granule cells by $\mathrm{CR}$ is a requirement for correct computation in the cerebellar cortex. 
A sequence of events in the CaBP-KO tested here has been hypothesized to result in the observed phenotype: (I) altered $\mathrm{Ca}^{2+}$ signaling in the Purkinje cells of $\mathrm{CB}-/-[12], \mathrm{PV}-/-$ and double-KO mice [39]; (II) changes in the firing properties of Purkinje cells resulting in an increased simple spike firing rate and the emergence of rhythmic activity of Purkinje cells that alters Purkinje cells neural code and facilitates the emergence of fast oscillation [35]; (III) disruption of functional cerebellar rostro-caudal functional organization.

Evidently CaBPs intervene at several levels of motor control including the peripheral nervous system (PNS), but currently no data is available on PNS alterations in the knockout strains tested here. The role of PV and CB in the PNS is likely to be revealed only in complex sensorimotor associative tasks rather than in simple locomotor tests. In conclusion, each of the genotype tested reveals subtle locomotor alterations, which are only observed when performing repeated tests. These small changes should not considerably affect the outcome of other behavioral tests related to the putative functions of these CaBPs in other brain regions.

\section{Acknowledgements}

We acknowledge the technical assistance of Simone Eichenberger, Line-Claude Chapuis and Aline Gioria from the Institute of Histology, Fribourg, and Christian Haeberli and Claude Verdan from the Institute of Physiology, University of Lausanne. We thank Dr. Michael Meyer, Ludwig-Maximilian University, Munich, Germany for providing the $\mathrm{CB}-/-$ mice. This work was partially supported by the Swiss National Science Foundation (grant no. 3100-047291.96 to M.R.C. and 3100A0 100400/1 to B.S.).

\section{References}

[1] Celio MR. Calbindin D-28k and parvalbumin in the rat nervous system. Neuroscience 1990;35:375-475.

[2] Celio M, Pauls T, Schwaller B, editors. Guidebook to the calcium-binding proteins, ISBN 0-19-859951-X edn. Oxford: Oxford University Press; 1996.

[3] Kawasaki H, Nakayama S, Kretsinger RH. Classification and evolution of EF-hand proteins. Biometals 1998;11:277-95.

[4] Schwaller B, Meyer M, Schiffmann S. 'New' functions for 'old' proteins: the role of the calcium-binding proteins calbindin D-28k, calretinin and parvalbumin, in cerebellar physiology. Studies with knockout mice. Cerebellum 2002;1:241-58.

[5] Andressen C, Blümcke I, Celio MR. Calcium-binding proteins: selective markers of nerve cells. Cell Tissue Res 1993;271:181-208.

[6] Baimbridge KG, Celio MR, Rogers JH. Calcium-binding proteins in the nervous system. Trends Neurosci 1992;15:303-8.

[7] Berggard T, Miron S, Onnerfjord P, Thulin E, Akerfeldt KS, Enghild JJ, et al. Calbindin D28k exhibits properties characteristic of a $\mathrm{Ca}^{2+}$ sensor. $\mathbf{J}$ Biol Chem 2002;277:16662-72.

[8] Schmidt H, Schwaller B, Eilers J. Calbindin D28k targets myo-inositol monophosphatase in spines and dendrites of cerebellar Purkinje neurons. Proc Natl Acad Sci USA 2005;102:5850-5.

[9] Fierro L, Llano I. High endogenous calcium buffering in Purkinje cells from rat cerebellar slices. J Physiol 1996;496:617-25.

[10] Celio MR, Heizmann CW. Calcium-binding protein parvalbumin is associated with fast contracting muscle fibres. Nature 1982;297:504-6.
[11] Schwaller B, Dick J, Dhoot G, Carroll S, Vrbova G, Nicotera P, et al. Prolonged contraction-relaxation cycle of fast-twitch muscles in parvalbumin knockout mice. Am J Physiol (Cell Physiol) 1999;276:C395-403.

[12] Airaksinen MS, Eilers J, Garaschuk O, Thoenen H, Konnerth A, Meyer M. Ataxia and altered dendritic calcium signaling in mice carrying a targeted null mutation of the calbindin D28k gene. Proc Natl Acad Sci USA 1997;94:1488-93.

[13] Molinari S, Battini R, Ferrari S, Pozzi L, Killcross AS, Robbins TW, et al. Deficits in memory and hippocampal long-term potentiation in mice with reduced calbindin D-28K expression. Proc Natl Acad Sci USA 1996;93:8028-33.

[14] Schwaller B, Tetko IV, Tandon P, Silveira DC, Vreugdenhil M, Henzi $\mathrm{T}$, et al. Parvalbumin deficiency affects network properties resulting in increased susceptibility to epileptic seizures. Mol Cell Neurosci 2004;25: 650-63.

[15] Caillard O, Moreno H, Schwaller B, Llano I, Celio MR, Marty A. Role of the calcium-binding protein parvalbumin in short-term synaptic plasticity. Proc Natl Acad Sci USA 2000;97:13372-7.

[16] Collin T, Chat M, Lucas MG, Moreno H, Racay P, Schwaller B, et al. Developmental changes in parvalbumin regulate presynaptic $\mathrm{Ca}^{2+}$ signaling. J Neurosci 2005;25:96-107.

[17] Vreugdenhil M, Jefferys JG, Celio MR, Schwaller B. Parvalbumindeficiency facilitates repetitive IPSCs and gamma oscillations in the hippocampus. J Neurophysiol 2003;89:1414-22.

[18] Magloczky Z, Halasz P, Vajda J, Czirjak S, Freund TF. Loss of calbindinD28K immunoreactivity from dentate granule cells in human temporal lobe epilepsy. Neuroscience 1997;76:377-85.

[19] Scotti AL, Bollag O, Kalt G, Nitsch C. Loss of perikaryal parvalbumin immunoreactivity from surviving GABAergic neurons in the CA1 field of epileptic gerbils. Hippocampus 1997;7:524-35.

[20] Roper SN, Eisenschenk S, King MA. Reduced density of parvalbumin- and calbindin D28-immunoreactive neurons in experimental cortical dysplasia. Epilepsy Res 1999;37:63-71.

[21] Vig PJ, Fratkin JD, Desaiah D, Currier RD, Subramony SH. Decreased parvalbumin immunoreactivity in surviving Purkinje cells of patients with spinocerebellar ataxia-1. Neurology 1996;47:249-53.

[22] Vig PJ, Subramony SH, Burright EN, Fratkin JD, McDaniel DO, Desaiah $\mathrm{D}$, et al. Reduced immunoreactivity to calcium-binding proteins in Purkinje cells precedes onset of ataxia in spinocerebellar ataxia-1 transgenic mice. Neurology 1998;50:106-13.

[23] Torrey EF, Barci BM, Webster MJ, Bartko JJ, Meador-Woodruff JH, Knable MB. Neurochemical markers for schizophrenia, bipolar disorder, and major depression in postmortem brains. Biol Psychiatr 2005;57:252-60.

[24] Reynolds GP, Abdul-Monim Z, Neill JC, Zhang ZJ. Calcium binding protein markers of GABA deficits in schizophrenia — postmortem studies and animal models. Neurotox Res 2004;6:57-61.

[25] Paulus MP, Dulawa SC, Ralph RJ, Mark AG. Behavioral organization is independent of locomotor activity in 129 and C57 mouse strains. Brain Res 1999;835:27-36.

[26] Vecellio M, Schwaller B, Meyer M, Hunziker W, Celio MR. Alterations in Purkinje cell spines of calbindin D-28k and parvalbumin knock-out mice. Eur J Neurosci 2000;12:945-54.

[27] Farré Castany MA, Mariéthoz C, Tetko IV, Schwaller B, Celio M, Villa AEP Role of parvalbumin and calbindin in locomotor behavior of knock-out mice. Eur J Neurosci 2000;12(Suppl 11):172.

[28] Simpson EM, Linder CC, Sargent EE, Davisson MT, Mobraaten LE, Sharp JJ. Genetic variation among 129 substrains and its importance for targeted mutagenesis in mice. Nat Genet 1997;16:19-27.

[29] Kashiwabuchi N, Ikeda K, Araki K, Hirano T, Shibuki K, Takayama C, et al. Impairment of motor coordination, Purkinje cell synapse formation, and cerebellar long-term depression in GluR delta 2 mutant mice. Cell $1995 ; 81: 245-52$

[30] Barski JJ, Hartmann J, Rose CR, Hoebeek F, Morl K, Noll-Hussong M, et al. Calbindin in cerebellar Purkinje cells is a critical determinant of the precision of motor coordination. J Neurosci 2003;23:3469-77.

[31] Jud C, Schmutz I, Hampp G, Oster H, Albrecht U. A guideline for analyzing circadian wheel-running behavior in rodents under different lighting conditions. Biol Proc Online 2005;7:101-16. 
[32] Contet C, Rawlins JN, Deacon RM. A comparison of 129S2/SvHsd and C57BL/6JOlaHsd mice on a test battery assessing sensorimotor, affective and cognitive behaviours: implications for the study of genetically modified mice. Behav Brain Res 2001;124:33-46.

[33] Silver R, Romero MT, Besmer HR, Leak R, Nunez JM, LeSauter J. Calbindin-D28K cells in the hamster SCN express light-induced Fos. Neuroreport 1996;7:1224-8.

[34] Logue SF, Owen EH, Rasmussen DL, Wehner JM. Assessment of locomotor activity, acoustic and tactile startle, and prepulse inhibition of startle in inbred mouse strains and F1 hybrids: implications of genetic background for single gene and quantitative trait loci analyses. Neuroscience 1997;80:1075-86.

[35] Servais L, Bearzatto B, Schwaller B, Dumont M, De Saedeleer C, Dan B, et al. Mono- and dual-frequency fast cerebellar oscillation in mice lacking parvalbumin and/or calbindin D-28k. Eur J Neurosci 2005;22:861-70.
[36] Schiffmann SN, Cheron G, Lohof A, d'Alcantara P, Meyer M, Parmentier $\mathbf{M}$, et al. Impaired motor coordination and Purkinje cell excitability in mice lacking calretinin. Proc Natl Acad Sci USA 1999;96: 5257-62.

[37] Cheron G, Gall D, Servais L, Dan B, Maex R, Schiffmann SN. Inactivation of calcium-binding protein genes induces $160 \mathrm{~Hz}$ oscillations in the cerebellar cortex of alert mice. J Neurosci 2004;24:434-41.

[38] Bearzatto B, Servais L, Roussel C, Gall D, Baba-Aissa F, Schurmans $\mathrm{S}$, et al. Targeted calretinin expression in granule cells of calretininnull mice restores normal cerebellar functions. FASEB J 2006;20: 380-2.

[39] Schmidt H, Stiefel KM, Racay P, Schwaller B, Eilers J. Mutational analysis of dendritic $\mathrm{Ca}^{2+}$ kinetics in rodent Purkinje cells: role of parvalbumin and calbindin D28k. J Physiol 2003;551:13-32. 